\title{
Effect of Adding Ketamine as An Adjuvant to Lidocaine in Ultrasound Guided Supraclavicular Brachial Plexus Block
}

\author{
Mohamed M. Shamlol, Saad EL-Din M. EL-Khateeb, Khaled M. Alaa Saleh \\ Department of Anesthesia \& Intensive Care, Faculty of Medicine, AL Azhar University \\ Corresponding author: Khaled M. Alaa Saleh; Mobile: 01113234579 Email: khaled.alaasaleh@gmail.com
}

\begin{abstract}
Background: Brachial plexus block is one of the most commonly used regional anesthetic techniques for postoperative analgesia. Its popularity originates in part from easily palpable landmarks and relative ease of placement. A number of adjuvants, such as ketamine, dexmedetomidine, and others have been studied to prolong the effect of supraclavicular brachial plexus block.

Aim of the Work: Evaluation of the effect of adding Ketamine as an adjuvant to lidocaine in ultrasoung guided supraclavicular brachial plexus block.

Patients and Methods: This randomized controlled study was conducted at the Department of Anesthesia, EL-Hussein Hospital, AL-Azhar university on 60 patients of ASA physical status I-II of either sex aged 1860 years. They were randomized into two equal groups 30 patients in each. Group A (Ketamine group): received $5 \mathrm{mg} / \mathrm{kg}$ lidocaine $2 \%$ and $2 \mathrm{mg} / \mathrm{kg}$ ketamine in a total volume $30 \mathrm{cc}$. Group B (Control group): received $5 \mathrm{mg} / \mathrm{kg}$ lidocaine $2 \%$ and saline in a total $30 \mathrm{cc}$.

Results: the study showed a significant increase in mean control group compared to ketamine group according to postoperative VAS.

Conclusion: Using of ultrasound led to decreasing the complications of supraclavicular brachial plexus block and adding ketamine as an adjuvant to lidocaine decreased the postoperative pain and the need for analgesics, without significant adverse effects. Therefore, it could be considered as an option to enhance the analgesic effects of the brachial plexus block.
\end{abstract}

Keywords: Ketamine, adjuvant, Lidocaine, US-guided supraclavicular brachial plexus block.

\section{INTRODUCTION}

Regional anaesthesia has many of the advantages reported when compared to general anesthesia for patients undergoing upper limb surgery, including improvement of peri-operative sedation, improved patient satisfaction, accelerated post-operative recovery (1), reduced housing consumption (2), reduced post-operative nausea and vomiting (PONV), short-term anesthesia unit (3) and early hospital discharge $(4,5)$. The supraclavicular nerve mass is ideal for upper limb procedures from the mid-humerus to the hand level. The brachial plexus is more complex at the level of its stem, formed from nerve roots C5-T1, so the blockade here has the greatest potential to block all branches of brachial plexus. This leads to rapid onset and ultimately high success rates for anesthesia, elbow clamping, forearm and hand surgery ${ }^{\left({ }^{6}\right)}$. The success of the clavicle nerve depends on the appropriate techniques for nerve stabilization, needle placement, and the concentration and size of local anesthesia used ${ }^{(7)}$. Recent studies showed that ultrasound guided masses have a faster onset and improved cluster quality with fewer complications than nonultrasound techniques, which rely on anatomical features to guide the needle ${ }^{(8)}$.

One of the most important benefits of realtime ultrasound imaging during peripheral nerve blockade is that deposition of LA can be readily appreciated during injection, and it allows the operator to distribute LA uniformly around the target nerve. This may reduce the amount of LA required to successfully block the nerves so reduce the risk of systemic LA toxicity and other complications ${ }^{(9)}$. Increasing the duration of local anesthetic action is often desirable because it prolongs surgical anesthesia and analgesia. Different additives have been used to prolong regional blockade. Vasoconstrictors, opioids, clonidine, verapamil etc. were added to local anesthetics, but the results were either inconclusive or associated with side effects ${ }^{(\mathbf{1 0})}$.

Ketamine is a noncompetitive antagonist of the N-methyl-D aspartate receptor (NMDAR). It is used for premedication, sedation, induction, and maintenance of general anesthesia. Central, regional, and local anesthetic and analgesic properties have been reported for ketamine. Intravenous (IV) administration of low-dose ketamine decreases postoperative opioid use and improves analgesia. The addition of ketamine to epidural lidocaine or bupivacaine increases the duration of regional anesthesia and post-operative analgesia. It has been seen that peri-incisional use of $0.3-0.5 \%$ ketamine combined with local anesthetic in surgical wounds enhances analgesia by a peripheral mechanism ${ }^{(11,12)}$.

There have been many advocated modifications of the original techniques. These 
modifications varied mostly according to site of insertion and its relationship with nerves such as infraclavicular, supraclavicular, axillary, perivascular infiltration and the sheath technique (14).

In 1978, it was reported the use of a Doppler flow ultrasound detector to facilitate supraclavicular blockade of the brachial plexus. To our knowledge, this was the first study in which an indirect sonographic approach was used for regional anesthesia. Since two-dimensional images could not be obtained with a high resolution. More advanced applications of ultrasound were out of reach at that time. The first report on direct sonographic visualization in regional anesthesia was in 1994. They investigated supraclavicular blockade of the brachial plexus in adults and even succeeded in viewing the spread of local anesthetic (15). Improvements in ultrasound technology during the past decade have made it possible to visualize even minute anatomical structures.

Today, the majority of anatomical structures and landmarks can be seen via ultrasound guidance even in young children ${ }^{(\mathbf{1 5})}$.

\section{AIM OF THE WORK}

Evaluation of the effect of ketamine added to lidocaine as regard onset, duration of sensory and motor block and post-operative pain in supraclavicular brachial plexus block for patients that were undergoing elective extremity surgery.

\section{PATIENTS AND METHODS}

The approval of the Medical Ethical Committee of AL-Azhar University and patient's formal consent were obtained. Sixty patients [ according to American Society of Anesthesiologists (ASA) physical status I or II] of either sex, aged 18-60 years were scheduled for elective or emergency forearm and hand surgeries. They were enrolled in this prospective controlled double blinded randomized study from May 2018 to December 2018.

\section{Inclusion Criteria:}

A. Age: $18-60$ years

B. Sex: both

C. American society of anesthesiology (ASA) : I or II

\section{Exclusion Criteria:}

1. Patient refusal.

2. Pregnant females.

3. Communications difficulties, which might prevent a reliable post-operative assessment.

4. Diseases affecting sensory or motor function, especially those with diabetic peripheral neuritis or had history of cerebral stroke with lesion affecting side of surgery.

5. Patient with upper limb neurological deficit.

6. Allergy to the local anesthetics.

7. Contraindications to supraclavicular nerve block (bleeding disorders and local or systemic infection).

8. Body mass index $(\mathrm{BMI})>35$.

9. History of pre-existing neuropathy, coagulopathy, hepatic or renal impairment, severe pulmonary disease.

10. Infection at the injection site.

11. Patients with expected duration of operation >120 minutes, patients in whom the block success was not obtained 30 minutes after injection, those who showed an allergic reaction to the drugs, and those who did not cooperate or were not willing to participate in the study.

\section{Sixty Patients were assigned to two equal groups:}

- Group I (Ketamine group): received $5 \mathrm{mg} / \mathrm{kg}$ body weight lidocaine $2 \%$ and $2 \mathrm{mg} / \mathrm{kg}$ body weight ketamine in a total volume $30 \mathrm{cc}$.

- Group II (Control group): received $5 \mathrm{mg} / \mathrm{kg}$ body weight lidocaine $2 \%$ and saline in a total volume $30 \mathrm{cc}$.

After explanation of the maneuver and applying routine monitors including electrocardiography (ECG), non-invasive arterial blood pressure, and pulse oximetry, intravenous access was secured with $18-\mathrm{G}$ cannula in the contralateral arm. Patients were positioned in the supine position with the face rotated to the contralateral side to facilitate performance of the block. Patients were given $2 \mathrm{mg}$ of midazolam intravenous (IV) as a premedication immediately before beginning. After sterilization of the area by betadine $10 \%$, all patients received $3 \mathrm{ml}$ lignocaine 2 $\%$ at the injection site, ultrasound-guided supraclavicular brachial plexus block were formed using a 22 Gauge $50 \mathrm{~mm}$ needle inserted in-plane with the ultrasound probe in the transverse cut. A Mindray Z5 was used to visualize the brachial plexus.

Post-operative analgesia was in the form of intravenous infusion of perfalgan $15 \mathrm{mg} / \mathrm{kg}$ when visual analogue scale (VAS) reach more than 4 repeated every 8 hours and if it reached $\geq 5$, intravenous Pethidine $0.3 \mathrm{mg} / \mathrm{kg}$ was given to the patient.

\section{Drugs used:}

$$
\begin{aligned}
& \text { - Lidocaine vial } 2 \% \\
& \text { - Ketamine vial } 50 \mathrm{mg} / \mathrm{ml}
\end{aligned}
$$




\section{Drugs for resustitation:}

- Atropine ampoule $1 \mathrm{mg} / \mathrm{ml} \&$ ephedrine

ampoule $25 \mathrm{mg} / \mathrm{ml}$

Equipments of resustitation:

- Cuffed endotracheal tube (internal

diameter $7.5 \mathrm{~mm}$ )

- Laryngeoscope

\section{Measuring variables}

All groups were assessed for efficacy of the block and adequacy of postoperative analgesia as follows:

\section{Intraoperative}

1) Block Evaluation

- The onset and depth of sensory block were evaluated by the same person at $5,10,15,20$, 25 and 30 minutes after the block. The extent of sensory blockade was tested by pinprick in the median, radial, ulnar, and musculocutaneous nerve distribution using a three point score: $2=$ normal sensation, $1=$ loss of sensation to pinprick ( loss of pain sensation), or $0=$ loss of sensation to light touch. Sensory block onset was defined as a decrease of sensation to grade 1 or less by comparison to the contralateral limb as a reference. Sensory block duration was defined as the time from injection of local anesthetic mixture to complete recovery of light touch and pain sensation as tested by a swab and pinprick respectively.

- Quality of motor block was evaluated using a 3 -point scale where $2=$ normal movement, $1=$ paresis (weak hand grip), and $0=$ absent movement. Onset of motor block was defined as the time from injection of local anesthetic mixture until achieving a reduction in motor power to grade 1 or less. Motor block duration was described as the time from injection of local anesthetic mixture to complete recovery of motor function.

- Block success was defined as loss of sensation to pinprick (sensory score 1 or less) in each of the radial, ulnar, median, and musculocutaneous nerve distributions measured within 30 mins after the end of local anesthetic injection. For patients in whom block success was not achieved after 30 mins general anesthesia was inducted, and the patient was excluded from data analysis.

2) Non invasive blood pressure (NIBP) and heart rate (HR) were monitored every 3 minutes through out the block and operation. They were recorded immediately before the block (baseline), every 15 minutes during the operation.

3) Respiratory rate and oxygen saturation were monitored through out the block and operation. They were recorded immediately before the block (baseline) and then every 15 minutes during the operation.

\section{Post-operative}

- Post-operative pain was evaluated by asking the patients to fill out a visual analogue scale (VAS) ${ }^{(16)}$ for pain. This was achieved by marking a $10 \mathrm{~cm}$ horizontal line anchored at one end a label "no pain" and the other end by a label the "worst pain imaginable", every two hours in the first 8 post-operative hours and then every 6 hours from 12 up to 36 hours after the block.

- Duration of postoperative analgesia in all groups was judged by the time from start of the block to the time of the first analgesic requirement.

- Total analgesic requirement in the first 36 hours was recorded.

- Non-invasive blood pressure (NIBP) and heart rate (HR) were recorded every two hours in the first 8 hours and then every 6 hours from 12 up to 36 hours after the block.

- Respiratory rate and oxygen saturation were checked every 2 hours in the first 12 hours.

- 48 hours after the surgery, patients were contacted to assess their satisfaction with their anaesthetic experience on a four-point scale (1 = unsatisfactory, 2 = partially satisfactory, $3=$ satisfactory and $4=$ excellent).

All groups were observed and assessed for incidence of complications as:

- Pneumothorax that was assessed by chest X ray immediately postoperative and 8 hours later.

- Hematoma or vascular injury that was assessed by ultrasound.

- Drug toxicity that was assessed by clinical manifestations of toxicity including seizures, profound hypotension and cardiac dysrhythmias.

- Hoarseness of voice due to block of the recurrent laryngeal nerve.

- Neuroaxial block.

- Horner's syndrome.

\section{Statistical analysis}

Recorded data were analyzed using the statistical package for social sciences, version 20.0 (SPSS Inc., Chicago, Illinois, USA). Quantitative data were expressed as mean \pm standard deviation (SD). Qualitative data were expressed as frequency and percentage.

\section{The following tests were done:}

- Independent-samples t-test of significance was used when comparing between two means. 
Effect of Adding Ketamine as An Adjuvant to Lidocaine...

- Chi-square $\left(\mathrm{x}^{2}\right)$ test of significance was used in order to compare proportions between qualitative parameters.

- The confidence interval was set to $95 \%$ and the margin of error accepted was set to $5 \%$. So, the p-value was considered significant as the following:
- Probability (P-value)

- P-value $<0.05$ was considered significant.

- P-value $<0.001$ was considered as highly significant.

- P-value > 0.05 was considered insignificant.

\section{RESULTS}

The results of the present study are demonstrated in the following tables:

Table (1): Comparison between group I and group II according to baseline characteristics.

\begin{tabular}{|c|c|c|c|c|}
\hline Baseline characteristics & $\begin{array}{l}\text { Group I: Ketamine } \\
\text { group }(n=30)\end{array}$ & $\begin{array}{l}\text { Group II: Control } \\
\text { group }(n=30)\end{array}$ & $\mathbf{t} / \mathbf{x} 2 \#$ & p-value \\
\hline $\begin{array}{l}\text { Age (years) } \\
\text { Range } \\
\text { Mean } \pm \text { SD }\end{array}$ & $\begin{array}{c}18-60 \\
37.18 \pm 10.89\end{array}$ & $\begin{array}{c}18-60 \\
38.28 \pm 14.30\end{array}$ & 0.623 & 0.461 \\
\hline $\begin{array}{l}\text { Sex } \\
\text { Male } \\
\text { Female }\end{array}$ & $\begin{array}{c}25(83.3 \%) \\
5(16.7 \%)\end{array}$ & $\begin{array}{l}22(73.3 \%) \\
8(26.7 \%)\end{array}$ & $0.850 \#$ & 0.629 \\
\hline $\begin{array}{l}\text { ASA } \\
\text { I } \\
\text { II }\end{array}$ & $\begin{array}{c}25(83.3 \%) \\
5(16.7 \%)\end{array}$ & $\begin{array}{c}24(80 \%) \\
6(20 \%) \\
\end{array}$ & $0.454 \#$ & 0.336 \\
\hline Weight (kg) & $79.83 \pm 10.61$ & $78.07 \pm 12.26$ & 0.369 & 0.273 \\
\hline BMI $\left(w t /(h t)^{\wedge} 2\right)$ & $25.75 \pm 3.30$ & $26.47 \pm 3.71$ & 0.230 & 0.170 \\
\hline $\begin{array}{l}\text { Duration of operation (min) } \\
\text { Range } \\
\text { Mean } \pm \text { SD }\end{array}$ & $\begin{array}{c}70-120 \\
80.85 \pm 29.70 \\
\end{array}$ & $\begin{array}{c}65-120 \\
78.40 \pm 30.80 \\
\end{array}$ & 0.241 & 0.178 \\
\hline $\begin{array}{l}\text { Type of operation } \\
\text { Elbow } \\
\text { Forearm } \\
\text { Hand }\end{array}$ & $\begin{array}{c}5(16.7 \%) \\
10(33.3 \%) \\
15(50 \%)\end{array}$ & $\begin{array}{c}4(13.3 \%) \\
9(30 \%) \\
17(56.7 \%)\end{array}$ & $0.666 \#$ & 0.492 \\
\hline
\end{tabular}

t-Independent Sample t-test; $x^{2}:$ Chi-square test $p$-value $>0.05 \mathrm{NS}$

This table showed no statistically significant difference between group I and group II according to baseline characteristics.

Table (2): Comparison between group I and group II according to onset (min).

\begin{tabular}{|l|c|c|c|c|}
\hline Onset (min) & $\begin{array}{c}\text { Group I: } \\
\text { Ketamine group } \\
(\mathbf{n = 3 0})\end{array}$ & $\begin{array}{c}\text { Group II: } \\
\text { Control group } \\
(\mathbf{n = 3 0})\end{array}$ & t-test & p-value \\
\hline Onset of sensory block (min) & $9.79 \pm 11.65$ & $7.81 \pm 2.81$ & 0.424 & 0.347 \\
\hline Onset motor block (min) & $13.56 \pm 4.04$ & $14.16 \pm 4.06$ & 1.070 & 0.878 \\
\hline
\end{tabular}

t-Independent Sample t-test, $p$-value $>0.05 \mathrm{NS}$

This table showed no statistically significant difference between group I and group II according to onset (min).

Table (3): Comparison between group I and group II according to duration (min)

\begin{tabular}{|l|c|c|c|c|}
\hline Duration (min) & $\begin{array}{c}\text { Group I: Ketamine } \\
\text { group }(\mathbf{n}=\mathbf{3 0})\end{array}$ & $\begin{array}{c}\text { Group II: Control } \\
\text { group (n=30) }\end{array}$ & t-test & p-value \\
\hline Duration of sensory block (min) & $215.79 \pm 34.29$ & $208.75 \pm 24.67$ & 0.402 & 0.329 \\
\hline Duration of motor block (min) & $244.01 \pm 31.46$ & $233.75 \pm 28.24$ & 0.208 & 0.170 \\
\hline
\end{tabular}

t-Independent Sample t-test

p-value $>0.05 \mathrm{NS}$

This table showed no statistically significant difference between group I and group II according to duration (min). 
Effect of Adding Ketamine as An Adjuvant to Lidocaine...

Table (3): Comparison between group I and group II according to mean arterial blood pressure (mmHg)

\begin{tabular}{|l|c|c|c|c|}
\hline $\begin{array}{l}\text { Mean Arterial blood pressure } \\
(\mathbf{m m H g})\end{array}$ & $\begin{array}{c}\text { Group I: } \\
\text { Ketamine group } \\
(\mathbf{n = 3 0})\end{array}$ & $\begin{array}{c}\text { Group II: } \\
\text { Control group } \\
(\mathbf{n = 3 0})\end{array}$ & t-test & p-value \\
\hline Baseline & $91.80 \pm 6.426$ & $95.88 \pm 6.712$ & 0.940 & 0.254 \\
\hline After 15 min. & $91.80 \pm 4.590$ & $94.86 \pm 4.743$ & 0.896 & 0.265 \\
\hline After 30 min. & $93.84 \pm 6.569$ & $93.84 \pm 6.569$ & 1.056 & 0.227 \\
\hline After 45 min. & $92.82 \pm 4.641$ & $96.90 \pm 4.845$ & 0.749 & 0.300 \\
\hline After 60 min. & $90.78 \pm 6.355$ & $91.80 \pm 6.426$ & 1.115 & 0.212 \\
\hline After 75 min. & $91.80 \pm 4.590$ & $92.82 \pm 4.641$ & 0.517 & 0.356 \\
\hline After 90 min. & $94.86 \pm 6.640$ & $90.78 \pm 6.355$ & 1.164 & 0.201 \\
\hline After 105 min. & $91.80 \pm 4.590$ & $92.82 \pm 4.641$ & 0.265 & 0.416 \\
\hline After 120 min. & $92.82 \pm 6.497$ & $94.86 \pm 6.640$ & 1.102 & 0.216 \\
\hline
\end{tabular}

\section{t-Independent Sample t-test}

p-value $>0.05 \mathrm{NS}$

This table showed no statistically significant difference between group I and group II according to mean arterial blood pressure.

Table (4): Comparison between group I and group II concerning the heart rate (Beat/min).

\begin{tabular}{|l|c|c|c|c|}
\hline Heart Rate (Beat/min) & $\begin{array}{c}\text { Group I: } \\
\text { Ketamine group } \\
(\mathbf{n = 3 0})\end{array}$ & $\begin{array}{c}\text { Group II: } \\
\text { Control group } \\
(\mathbf{n = 3 0})\end{array}$ & t-test & p-value \\
\hline Baseline & $87.87 \pm 4.83$ & $85.85 \pm 4.72$ & 0.935 & 0.256 \\
\hline After 15 min. & $85.85 \pm 4.38$ & $86.86 \pm 4.43$ & 0.748 & 0.301 \\
\hline After 30 min. & $87.87 \pm 4.48$ & $84.84 \pm 4.33$ & 0.853 & 0.275 \\
\hline After 45 min. & $85.85 \pm 4.72$ & $86.86 \pm 4.78$ & 0.826 & 0.282 \\
\hline After 60 min. & $84.84 \pm 4.33$ & $85.85 \pm 4.38$ & 0.884 & 0.268 \\
\hline After 75 min. & $85.85 \pm 4.38$ & $85.85 \pm 4.38$ & 0.989 & 0.243 \\
\hline After 90 min. & $83.83 \pm 4.61$ & $84.84 \pm 4.67$ & 0.250 & 0.420 \\
\hline After 105 min. & $84.84 \pm 4.33$ & $84.84 \pm 4.33$ & 0.646 & 0.325 \\
\hline After 120 min. & $85.85 \pm 4.38$ & $83.83 \pm 4.28$ & 1.049 & 0.228 \\
\hline
\end{tabular}

t-Independent Sample t-test

p-value $>0.05 \mathrm{NS}$

This table showed no statistically significant difference between group I and group II concerning the heart rate.

Table (5): Comparison between group I and group II regarding the respiratory rate.

\begin{tabular}{|l|c|c|c|c|}
\hline Respiratory Rate & $\begin{array}{c}\text { Group I: } \\
\text { Ketamine group } \\
(\mathbf{n = 3 0 )}\end{array}$ & $\begin{array}{c}\text { Group II: } \\
\text { Control group } \\
(\mathbf{n = 3 0 )}\end{array}$ & t-test & p-value \\
\hline After 4hrs & $15.15 \pm 1.36$ & $15.91 \pm 1.43$ & 1.075 & 0.222 \\
\hline After 5hrs & $14.28 \pm 1.29$ & $14.99 \pm 1.35$ & 0.860 & 0.274 \\
\hline After 6hrs & $15.15 \pm 1.36$ & $15.91 \pm 1.43$ & 0.981 & 0.245 \\
\hline After 7hrs & $14.14 \pm 1.27$ & $14.85 \pm 1.34$ & 0.949 & 0.252 \\
\hline After 8hrs & $14.28 \pm 1.29$ & $14.99 \pm 1.35$ & 1.017 & 0.236 \\
\hline After 9hrs & $15.15 \pm 1.36$ & $15.91 \pm 1.43$ & 1.137 & 0.207 \\
\hline After 10hrs & $15.30 \pm 1.38$ & $16.07 \pm 1.45$ & 0.287 & 0.411 \\
\hline After 11hrs & $14.14 \pm 1.27$ & $14.85 \pm 1.34$ & 0.742 & 0.302 \\
\hline After 12hrs & $14.14 \pm 1.27$ & $14.85 \pm 1.34$ & 1.206 & 0.191 \\
\hline
\end{tabular}

t-Independent Sample t-test; p-value >0.05 NS

This table showed no statistically significant difference between group I and group II regarding the respiratory rate. 
Table (6): Comparison between group I and group II according to SPo2.

\begin{tabular}{|l|c|c|c|c|}
\hline SPO2 & $\begin{array}{c}\text { Group I: } \\
\text { Ketamine group } \\
(\mathbf{n = 3 0})\end{array}$ & $\begin{array}{c}\text { Group II: } \\
\text { Control group } \\
(\mathbf{n = 3 0 )}\end{array}$ & t-test & p-value \\
\hline After 4hrs & $99.55 \pm 0.69$ & $99.40 \pm 0.60$ & 0.699 & 0.312 \\
\hline After 5hrs & $99.35 \pm 0.81$ & $99.65 \pm 0.49$ & 0.559 & 0.346 \\
\hline After 6hrs & $99.55 \pm 0.60$ & $99.10 \pm 0.85$ & 0.638 & 0.327 \\
\hline After 7hrs & $99.40 \pm 0.68$ & $99.30 \pm 0.66$ & 0.617 & 0.332 \\
\hline After 8hrs & $99.35 \pm 0.81$ & $99.65 \pm 0.49$ & 0.661 & 0.321 \\
\hline After 9hrs & $99.55 \pm 0.60$ & $99.35 \pm 0.59$ & 0.739 & 0.303 \\
\hline After 10hrs & $99.68 \pm 0.27$ & $99.59 \pm 0.35$ & 0.187 & 0.435 \\
\hline After 11hrs & $99.40 \pm 0.75$ & $98.80 \pm 0.89$ & 0.483 & 0.364 \\
\hline After 12hrs & $99.35 \pm 0.75$ & $99.40 \pm 0.60$ & 0.784 & 0.292 \\
\hline
\end{tabular}

$t$-Independent Sample $t$-test; $p$-value $>0.05 \mathrm{NS}$

This table showed no statistically significant difference between group I and group II according to SPO2.

Table (7): Comparison between group I and group II according to post-operative VAS.

\begin{tabular}{|l|c|c|c|c|}
\hline Postoperative VAS & $\begin{array}{c}\text { Group I: } \\
\text { Ketamine group } \\
(\mathbf{n = 3 0})\end{array}$ & $\begin{array}{c}\text { Group II: } \\
\text { Control group } \\
(\mathbf{n = 3 0})\end{array}$ & t-test & p-value \\
\hline Arrival to recovery & $0.70 \pm 0.68$ & $1.42 \pm 1.04$ & 3.49 & $\mathbf{0 . 0 2 4} *$ \\
\hline After 30min. & $0.81 \pm 0.70$ & $1.66 \pm 0.77$ & 3.84 & $\mathbf{0 . 0 1 7} *$ \\
\hline After 1hr. & $1.42 \pm 0.81$ & $3.15 \pm 1.35$ & 4.23 & $\mathbf{0 . 0 0 4} *$ \\
\hline After 6hrs. & $2.28 \pm 1.11$ & $3.96 \pm 1.45$ & 4.65 & $<\mathbf{0 . 0 0 1} * *$ \\
\hline After 12 hrs. & $2.55 \pm 1.31$ & $3.96 \pm 1.31$ & 5.12 & $<\mathbf{0 . 0 0 1} * *$ \\
\hline After 24 hrs. & $1.68 \pm 0.98$ & $3.15 \pm 1.26$ & 5.63 & $<\mathbf{0 . 0 0 1} * *$ \\
\hline
\end{tabular}

t-Independent Sample t-test;

${ }^{*} p$-value $<0.05 \mathrm{~S}$;**p-value $<0.001 \mathrm{HS}$

This table showed statistically significant increase in mean control group compared to ketamine group according to post-operative VAS.

Table (8): Comparison between group I and group II according to time of first dose and total pethidine dose.

\begin{tabular}{|l|c|c|c|c|}
\hline & $\begin{array}{c}\text { Group I: } \\
\text { Ketamine group } \\
(\mathbf{n = 3 0})\end{array}$ & $\begin{array}{c}\text { Group II: } \\
\text { Control group } \\
(\mathbf{n = 3 0})\end{array}$ & t-test & p-value \\
\hline Time of first dose (min) & $396.48 \pm 111.62$ & $217.88 \pm 77.28$ & 10.502 & $<\mathbf{0 . 0 0 1} * *$ \\
\hline Total pethidine dose $(\mathrm{mg})$ & $115.29 \pm 41.58$ & $177.56 \pm 47.04$ & 7.280 & $<\mathbf{0 . 0 0 1} * *$ \\
\hline
\end{tabular}

$t$-Independent Sample t-test;

${ }^{*}$-value $<0.05 \mathrm{~S} ; * *$-value $<0.001 \mathrm{HS}$

This table showed statistically significant decrease in mean control group compared to ketamine group according to time of first dose ( $\mathrm{min}$ ) and showed statistically significant increase in mean control group compared to ketamine group according to total pethidine dose (mg).

\section{Complications:}

- Failure of brachial plexus block occurred in 3 patients and they were excluded from the study.

- Haematoma at site of needle insertion occurred in five patients and treated with cold fomentation and hemoclar cream.

- Allergic reaction occurred in one patient and treated with solu-cortef vial $(100 \mathrm{mg})$, dexamethasone ampoule (8 $\mathrm{mg})$ and ephedrine ampoule $(25 \mathrm{mg})$ and the patient was excluded from the study.

\section{DISCUSSION}

The addition of ketamine to $2 \%$ lidocaine to the brachial plexus mass does not change the time and duration of sensory or motor mass, but could reduce pain after surgery. Ketamine is a phencyclidine derivative that has various central effects through the $\mathrm{N}$ methyl-D-aspartate (NMDA) receptor. It is used for premedication, sedation, induction, and maintenance of general anesthesia. IV administration of ketamine provides significant postoperative analgesia through its 
central mechanism ${ }^{(\mathbf{1 7})}$. The role of a sub-anesthetic dose of ketamine as an anti-hyperalgesic or antiallodynic agent has recently gained increasing interest in pain management ${ }^{(\mathbf{1 8})}$.

Previous studies indicated that the addition of ketamine $(10-50 \mathrm{mg})$ to epidural bupivacaine or lidocaine prolongs the duration of regional anesthesia. They suggested that the enhancement of lidocaine epidural anesthesia by ketamine is more likely the result of the direct action of ketamine on the nerve root fibers rather than the action on the spinal cord.

Local anesthetic properties of ketamine were demonstrated by Dowdy et al. ${ }^{(19)}$ who reported that ketamine could produce reversible inhibition of the compound action potential in the stimulated frog sciatic nerve. In addition, dogs injected with ketamine rapidly developed reversible segmental paralysis (with no alteration of the state of consciousness). The effect of ketamine on nerve conduction was confirmed by Weber et al. ${ }^{(20)}$ who reported that the subcutaneous infiltration of ketamine caused a loss of thermal and pain sensations for eight to ten minutes.

In this study, the addition of ketamine to lidocaine solution did not improve the onset or duration of sensory or motor block. Similarly, Lee et al. ${ }^{(21)}$ showed that $30 \mathrm{mg}$ of ketamine added to $30 \mathrm{ml}$ of $0.5 \%$ ropivacaine in the brachial plexus block, did not improve the onset time or duration of sensory and motor block. However, contrary to the study of Lee $\boldsymbol{e t}$ al. ${ }^{(21)}$, post-operative pain and need for analgesics in the ketamine group were decreased in this study. We did not have a clear explanation for this result. The analgesic effect could be the result of the local anesthetic effect of ketamine at the level of surgical trauma. Tverskoy et al. (22) showed that in patients whose wounds were infiltrated with a solution of bupivacaine $0.5 \%$ and ketamine $0.3 \%$, there were enhancement of the local anesthetic and analgesic effects of bupivacaine that could not be explained by a central action of ketamine. Therefore, this effect was most likely peripheral.

Previously published studies suggested that the effect of ketamine is more likely to occur locally in an inflamed tissue, but not at the level of a nerve plexus distant from the surgical site. Ketamine demonstrated a significant anti-inflammatory effect that significantly inhibits the early postoperative inflammatory response. It can act at different levels of inflammation, interacting with inflammatory cell recruitment, cytokine production, and inflammatory mediator regulation ${ }^{(23)}$. Although we explained the peripheral effects for ketamine, the central mechanisms could not be rolled out in this study. The role of N-methyl-D-aspartate receptor (NMDAR) in processing the nociceptive input could explain the analgesic properties of ketamine. The N-methyl-Daspartate receptor (NMDAR) is an excitatory glutamatergic receptor in the spinal and supraspinal sites involved in the afferent transmission of nociceptive signals. Other effects of ketamine that might contribute to its systemic analgesic behavior include, enhancement of the descending inhibition, interaction with other receptors, including the $\mu$ opioid receptor, anti-inflammatory effects, and effect on the N-methyl-D-aspartate (NMDAR) at presynaptic sites ${ }^{(24)}$.

In contrast, in some studies, the addition of ketamine to local anesthetics did not improve the peripheral, regional, or local analgesia. Rahimzadeh et al. ${ }^{(25)}$ compared the analgesic effects of peri-femoral nerve infusion of ketamine plus ropivacaine versus ropivacaine, after operation, in patients who underwent elective knee surgery for repairing the anterior cruciate ligament (ACL), under spinal anesthesia. They reported that the addition of ketamine $1 \mathrm{mg} / \mathrm{kg}$ to $0.1 \%$ ropivacaine could not improve postoperative pain relief in the first 48 hours after the operation. Zohar et al. (26) reported that ketamine added to local bupivacaine did not enhance analgesia after wound infiltration following Cesarean section.

Besides, it was reported that the addition of ketamine to local anesthetics failed to improve analgesia after intra-articular injection for knee arthroscopy ${ }^{(27)}$ and its addition to bupivacaine for nerve block and wound infiltration after inguinal hernia repair did not improve postoperative pain relief significantly ${ }^{(28)}$.

Lashgarinia et al. ${ }^{(29)}$ concluded that adding ketamine in a dose of $2 \mathrm{mg} / \mathrm{kg}$ to lidocaine $5 \mathrm{mg} / \mathrm{kg}$ $1.5 \%$ in ultrasound-guided brachial plexus block could decrease the postoperative pain and need for analgesia most probably due to the local anesthetic effect of ketamine at the level of surgical trauma.

The variable effect of ketamine in various studies probably came from the different ketamine concentrations and sites of injection. We administered 100-200 mg ketamine that was more than what the previously mentioned studies had used and the complications and alterations in the level of consciousness were minor and transient.

This study showed that ketamine decreased the severity of postoperative pain until 24 hours after surgery. Tverskoy and colleagues ${ }^{(22)}$ reported that the effect of ketamine on the inhibition of central sensitization could be explained by the long-lasting analgesic effect of ketamine on post-operative pain where the analgesic efficacy of ketamine when added to bupivacaine infiltration before inguinal hernia repair lasted for one week after infiltration.

\section{CONCLUSION}

Our study showed that the addition of ketamine 2 $\mathrm{mg} / \mathrm{kg}$ body weight to lidocaine in the brachial plexus 
block did not improve the onset and duration of the sensory or motor block, but it decreased the postoperative pain and need for analgesics without significant adverse effects. Therefore, it could be considered as an option to enhance the analgesic effects of the brachial plexus block.

\section{REFERENCES}

1. O'Donnell B, Wilton R (2009): Ultrasound-Guided Axillary Brachial Plexus Block with 20 Milliliters Local Anaesthetic Mixture Versus General Anaesthesia for Upper Limb Trauma Surgery. Anaesth Analg., 109: 279-83.

2. Richman J, Courpas G, Wong R (2006): Does continuous peripheral nerve block provide superior pain control to opioids? A metaanalysis. Anaesth Analg., 102: 248-57.

3. Liu S, trodbeck W, Richman J (2005): A comparison of regional versus general anaesthesia for ambulatory anaesthesia: a meta-analysis of randomized controlled trials. Anaesth A WB Analg., 101: 1634-42.

4. Hadzic, Karaca PE, Hobeika P, Unis G, Dermk.sian J, Yufa M, Thys DM (2005): Santos AC For outpatient rotator cuff surgery nerve block anaesthesia provides superior sameday recovery over general anaesthesia. Anaesthesiology, 102: 1001-7.

5. McCartney Q, Brull R, Chan V (2004): Early but no longterm benefit of regional compared with general anaesthesia for ambulatory hand surgery. Anaesthesiology, 101: 461-7.

6. Chin K, Singh M, Velayutham V (2010): Infraclavicular brachial plexus block for regional anaesthesia of the lower arm. Anaesth Analg., 111 (4): 1072

7. Joseph M, Neal M, James R (2002): The Brachial Plexus. Regional Anaesthesia and Pain Medicine, 27: 402-28.

8. Jeon D, Kim W (2010): ultrasound-guided supraclavicular block in 105 patients. Korean J Anaesthesiol., 58 (3): 267-71.

9. Duggan E, Beheiry HE, Perlas A, Lupu M, Nuica A (2009): Minimum Effective Volume of Local Anaesthetic for Ultrasound-Guided Supraclavicular Brachial Plexus Block. Reg Anaesth Pain Med., 34: 215-8.

10. Wakhlo R, Gupta V, Raina A, Gupta SD, Lahori VU (2009): Supraclavicular Plexus Block: Effect of Adding Tramadol or Butorphanol as an Adjuncts to Local Anaesthetic on Motor and Sensory Block and Duration of Post-operative Analgesia. J Anaesth Clin Pharmacol., 25 (1): $17-20$.

11. Haas DA, Harper DG (1992): Ketamine: A review of its pharmacologic properties and use in ambulatory anesthesia. Anesth Prog., 39: 61-8.

12. Tverskoy M, Oren M, Vaskovich M, Dashkovsky I, Kissin I (1996): Ketamine enhances local anesthetic and analgesic effects of bupivacaine by peripheral mechanism: A study in postoperative patients. Neurosci Lett., 215: 5-8.

13. Boezzart A, DeBeer J, Mercia L (2003): Early continuous cervical paravertebral block using a stimulating catheter. Regional Anesthesia Pain Medical, 26: 129-139.

14. Bridenbaugh LD (2004): The upper extremity, somatic block. In : Cousins, M.J. and Briedenbaugh, P.O. Neural blockade in clincial anesthesia and management of pain. 2nd edition. Lippincott-Raven, Philadelphia, pp: 396-423.

15. Kapral S, Krafft P, Eibenberger K et al. (2003): Ultrasoundguided supraclavicular approach for regional anesthesia of the brachial plexus. Anesthesia Analg., 78: 507-513
16. Brown D (2009): Principles of Acute Pain Assessment In: Felicia Cox (editor): Perioperative Pain Management. 1st ed., by Blackwell Publishing Ltd., pp: 17-44.

17. Reves JG, Glass PS, Lubarsky DA, McEvoy MD, Martinez R R (2009): Intravenous Anesthetics. In: Miller R, editor. Miller's Anesthesia. 7th ed. Orlando: Churchill Livingstone, pp: 225.

18. Argiriadou H, Papagiannopoulou P, Foroulis CN, Anastasiadis K, Thomaidou E, Papakonstantinou $\mathrm{C}$ et al. (2011): Intraoperative infusion of $S(+)$-ketamine enhances post-thoracotomy pain control compared with perioperative parecoxib when used in conjunction with thoracic paravertebral ropivacaine infusion. $\mathrm{J}$ Cardiothorac Vasc Anesth., 25: 455-61.

19.Dowdy EG, Kaya K, Gocho Y (1973): Some pharmacologic similarities of ketamine, lidocaine, and procaine. Anesth Analg., 52: 839-42.

20. Weber WV, Jawalekar KS, Jawalekar SR (1975): The effect of ketamine on nerve conduction in isolated sciatic nerves of the toad. Neurosci Lett., 1: 115-20.

21. Lee IO, Kim WK, Kong MH, Lee MK, Kim NS, Choi YS et al. (2002): No enhancement of sensory and motor blockade by ketamine added to ropivacaine interscalene brachial plexus blockade. Acta Anaesthesiol Scand., 46: 8216.

22. Tverskoy M, Oren M, Vaskovich M, Dashkovsky I, Kissin I (1996): Ketamine enhances local anesthetic and analgesic effects of bupivacaine by peripheral mechanism: A study in postoperative patients. Neurosci Lett., 215: 5-8.

23. Dale O, Somogyi AA, Li Y, Sullivan T, Shavit Y (2012): Does intraoperative ketamine attenuate inflammatory reactivity following surgery? A systematic review and metaanalysis. Anesth Analg., 115: 934-43.

24. Niesters M, Martini C, Dahan A (2014): Ketamine for chronic pain: Risks and benefits. Br J Clin Pharmacol., 77: 357-67.

25. Rahimzadeh P, Faiz SH, Ziyaeifard M, Niknam K (2013): Effectivness of adding ketamine to ropivacaine infusion via femoral nerve catheter after knee anterior cruciate ligament repair. J Res Med Sci., 18: 632-6.

26.Zohar E, Luban I, Zunser I, Shapiro A, Jedeikin R, Fredman B (2002): Patient-controlled bupivacaine wound instillation following cesarean section: The lack of efficacy of adjuvant ketamine. J Clin Anesth., 14: 505-11.

27. Rosseland LA, Stubhaug A, Sandberg L, Breivik H (2003): Intra-articular (IA) catheter administration of postoperative analgesics. A new trial design allows evaluation of baseline pain, demonstrates large variation in need of analgesics, and finds no analgesic effect of IA ketamine compared with IA saline. Pain, 104: 25-34.

28. Clerc S, Vuilleumier H, Frascarolo P, Spahn DR, Gardaz JP (2005): Is the effect of inguinal field block with $0.5 \%$ bupivacaine on postoperative pain after hernia repair enhanced by addition of ketorolac or $\mathrm{S}(+)$ ketamine? Clin J Pain, 21: 101-5.

29. Lashgarinia $M$, Naghibi $K$, Honarmand A, Safavi $M$, Mehdi K (2014): Effect of ketamine as an adjuvant in ultrasound-guided supraclavicular brachial plexus block: A double-blind randomized clinical trial study. Adv Biomed Res.,

3:

232. 